\title{
Evaluation of Performance and Challenges of Use of Waste Materials in Pavement Construction: A Critical Review
}

\author{
Ali Jamshidi * and Greg White \\ School of Science and Engineering, University of Sunshine Coast, 4556 Sippy Downs, Australia; \\ gwhite2@usc.edu.au \\ * Correspondence: ajamshidi@usc.edu.au
}

Received: 19 November 2019; Accepted: 25 December 2019; Published: 27 December 2019

\begin{abstract}
Paved surfaces must reliably bear heavy loads, often under challenging environmental and geotechnical conditions. These requirements are addressed through the use of high-quality, newly produced materials in pavement design. However, in remote locations, newly produced materials are often expensive or unavailable, making waste or alternative materials more attractive. Waste materials can be used in their natural condition but are more commonly stabilised or otherwise improved to meet performance targets. However, this practice can incorporate unwarranted risk into pavement design solutions. The decision to use waste materials in a pavement is a balance between technical risk, maintenance liability, available materials, environmental emissions and capital cost. This study reviews the use of waste materials in pavement design and construction. Reclaimed asphalt pavement (RAP) materials and processed waste plastic for pavement construction are considered. Additionally, blast furnace slag (BFS) and waste glass in pavement construction are evaluated. This review focuses on the effects of alternative materials on the properties of asphalt pavement. The results indicate that RAP is acceptable as an alternative material, while BFS, waste plastic and waste glass can be used under specific conditions. Also, the current and future challenges for the use of waste materials in the pavement industry are discussed.
\end{abstract}

Keywords: sustainable pavement; energy efficiency; waste materials

\section{Introduction}

The productivity and efficiency of transportation infrastructure assets significantly depends on the structural and functional performance of pavement networks, including highways, airports and ports. High-quality materials and advanced technologies are typically used in the construction of new pavement. However, pavement construction places a significant burden on non-renewable natural resources, including quarried aggregate sources and carbon-based energy carriers such as industrial fuel and bituminous binder. To reduce the environmental impact of pavement design and construction, increasing the sustainability of paving materials and construction technologies is desired.

Environmentally sustainable opportunities in pavement construction are assessed via a range of environmental rating tools such as life cycle analysis (LCA) and leadership in energy and environmental design (based on ISO 14044). One of most effective approaches for the construction of sustainable pavement is the use of waste materials such as reclaimed, recycled and waste products. Notably, a variety of different waste materials can be used in various layers of a pavement system; however, one must consider a number of factors when determining the appropriate use of waste materials in pavement construction. 
Suitability of waste materials must be determined through objective experimentation because each material possesses unique attributes which contribute to the structural performance of a paving system. The optimal type and amount of the waste material should also be verified via field investigation and/or full-scale tests when possible. The following factors must be considered when incorporating waste materials into pavement construction:

\subsection{Pavement Type}

Pavements can be separated into three primary types: rigid (concrete), flexible (asphalt) and hybrid (stabilised cement and surfaced asphalt). Although flexible pavements usually have asphalt surfaces, sprayed seals and interlocking concrete block pavers are also viable surface solutions. The load-bearing capacity of concrete block paving systems is based on horizontal, vertical and rotational interlocking, whereas in concrete pavements, it depends on the slab-action of the concrete. Concurrently, asphalt ageing and progressive interlocking due to compaction and field densification are factors influencing the load-bearing capacity of asphalt surfaces.

\subsection{Pavement Strength}

Pavements containing waste materials should have a structural strength equivalent to similarly comprised traditional materials. In other words, the waste materials should meet the structural strength requirements prescribed for conventional pavement construction.

\subsection{Material Performance}

The performance of pavements is evaluated using various laboratory tests including rutting, fatigue, moisture sensitivity, indirect tensile strength and fracture tests. In addition, rheological tests including a temperature sweep and a Multiple Stress Creep Recovery (MSRC) are carried out to better gauge the effects of waste materials on the viscoelastic characteristics of unaged and aged bituminous binders.

\subsection{Initial Cost}

The costs associated with material supply and processing must be considered. For example, a lack of infrastructure for recovering and processing the requisite materials may increase initial costs.

\subsection{Life Cycle Cost}

The pavement life cycle consists of four main phases: raw material, construction, utility (or service) and recycling. Since pavement life should be considered a closed-loop system for increasing sustainability, the effects of waste materials on each phase are typically analysed. Moreover, the environmental impact and socio-economic cost of pavement alternatives should be assessed. Two different types of costs are incurred by the development of pavement systems, namely, agency costs and user costs. Agency costs encompass raw material processing, construction maintenance/rehabilitation and recycling [1], whereas pavement user costs usually consist of vehicle operation, delay and accident costs [2].

\subsection{Durability}

Waste materials should have comparable durability to new materials against environmental conditions and corrosion. For example, pavements constructed using waste materials at airports should be resistant to jet aircraft exhaust.

\subsection{Practicability}

The practical tolerances typically prescribed by construction standards should be met by pavements containing waste materials. 


\subsection{Constructability}

It is necessary to evaluate whether the construction and paving crews require any particular skills or equipment to meet the construction, maintenance and rehabilitation tolerances associated with waste materials.

\subsection{Safety}

Safety must be addressed in all phases of pavement life. For example, waste materials must be screened for any hazardous effects on the health of paving crews. Moreover, pavement constructed using waste materials must allow for safe transportation of passengers and commodities (e.g., pavement surfaces containing waste materials must provide adequate skid resistance).

\subsection{Effects of Climate Change}

Influences of climate change can be divided into two primary modes: direct and indirect effects [3]. Direct effects are due to environmental impacts such as temperature, precipitation, wind speed and aquifer level, while indirect effects cover changes in traffic load caused by demographic changes resulting from climate change [4,5].

\subsection{Waste Material Option}

Design and construction of pavements incorporating waste materials requires a balance between all of the aforementioned factors. In this study, the performances of four different waste materials (reclaimed asphalt pavement (RAP), processed waste plastic, blast furnace slag (BFS) and recycled (cullet) glass) are considered in terms of suitability for use as materials in pavement construction. Load-bearing capability and material mechanisms were also investigated. The discussion provides a basis of comparison for pavement engineers and researchers considering alternative waste materials for various paving applications.

\section{Recycled Material Analysis}

\subsection{Recycled Asphalt Pavement}

The first instance of asphalt pavement recycling dates back to 1915 with the Warren Brothers portable asphalt plant [6]. However, it was the oil crisis in the early 1970s that increased asphalt price and energy costs, which truly incentivised increased RAP use [7]. RAP is currently ranked as a highly desirable material for use as an economic, technical and environmentally advantageous waste material in pavement construction. It is preferred over other waste materials including fly ash, rubber tires, steel slag, bottom ash, waste glass, building rubble and incinerator residue [5]. Presently, $99 \%$ of RAP generated in the USA is reused; 460 million tons of crushed aggregate is used for paving works each year [8,9]. Likewise, in Japan, $99 \%$ of all RAP is reused in new pavement construction [10]. RAP is reused at an impeccable 100\% rate in Denmark and Sweden [9]. However, Flemish road standard SB250 in Belgium disallows the use of RAP in the surface course of road pavement because of the environmental impact of potential leachates [11]. The incorporation of RAP as an alternative material in asphalt base and sub-base layer construction offers the potential for reducing global warming $(20 \%)$, energy consumption $(16 \%)$, water consumption $(11 \%)$, life cycle costs $(21 \%)$ and hazardous waste generation (11\%) [12].

The primary technical advantage of asphalt mixes containing RAP is higher stiffness resulting from the combination of a virgin asphalt binder with an aged (hardened) asphalt binder. The resulting blended binder has a higher stiffness than the virgin binder because of higher activation energy [13-15]. In other words, the aged asphalt binder increases the stiffness of the blended asphalt binder [16], which results in an increase in the dynamic modulus and indirect tensile strength of the asphalt mixture $[17,18]$ (Figure 1). The slope of indirect tensile strength (ITS) indicates that each additional 
percent of RAP increases the ITS of the mixture by $13 \mathrm{kPa}$. Moreover, the binder content in the RAP reduces the optimum new binder content $(\mathrm{OBC})$. Figure 1 demonstrates the inverse relation between the OBC and RAP concentration. Therefore, incorporation of RAP not only increases the structural capacity of the asphalt mixture in terms of dynamic modulus and ITS, it also reduces the required volume of the new binder, resulting in greater sustainability benefits.

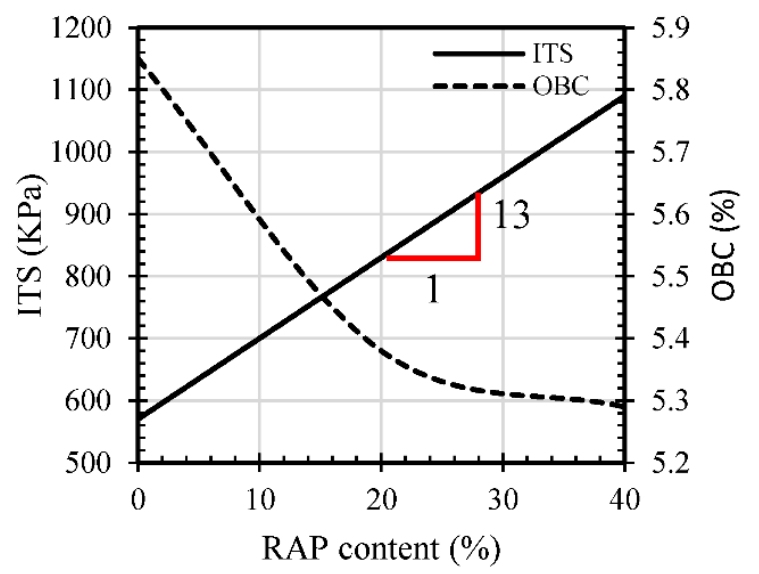

Figure 1. Correlation between ITS and OBC and RAP content based on data reported by Hajj et al. [19].

Although higher stiffness is an advantage for mix performance at higher temperatures, this attribute is a disadvantage at lower temperatures because of the increased potential for cracking and intermediate temperature fatigue (Figure 2). The construction temperature of mixes incorporating RAP is typically higher than that of traditional hot asphalt without RAP, which results in greater degrees of ageing, fatigue and susceptibility to low temperature cracking. However, the crack-resistance of asphalt mixes can be improved using fibreglass, which bridges the microcracks formed in the mix [20].

To avoid high stiffness, using lower quantities of RAP is recommended. Furthermore, some asphalt production plants now incorporate the RAP after the new aggregates are heated, thereby reducing the additional ageing induced by the RAP binder. Therefore, optimal RAP content is determined based on the rheological properties of the recovered asphalt binder and the engineering properties of the mixture and additives (such as antistripping agents or asphalt modifiers). For example, Figure 2 illustrates that approximately $10 \%$ RAP is an ideal concentration in terms of fatigue for both binder types. A softer binder can be used to compensate for the increased stiffness caused by the inclusion of RAP materials and to improve resilience to fatigue and low-temperature cracking. Figure 2 demonstrates that the fatigue life of mixtures produced using PG 52-34 and 10\% RAP is approximately 11 times higher than a similar mix produced using the harder PG 64-22 binder. To reduce the hardness of the mix, a rejuvenator can be added; for instance, Daryaee et al., [21] found that a rejuvenator improved fatigue life and moisture resistance in a mix containing 50\% RAP.

To address the environmental issues associated with the high construction temperatures when using RAP, warm mix asphalt (WMA) technology can be utilized. Different WMA technologies use additives or foamed bitumen to decrease mixing and compaction temperatures of asphalt. Experimental results showed that an Evotherm ${ }^{\circledR}$ WMA incorporating 50\% and 75\% RAP displayed better performance in terms of ITS, dynamic modulus and rutting compared to a control mix and several WMA samples incorporating 25\% RAP [22]. Furthermore, Martinho et al. [23] found that WMA samples produced with different WMA additives including Sasobit ${ }^{\circledR}$, Rediset ${ }^{\circledR}$ and Viatop ${ }^{\circledR}$, each incorporating 35\% RAP, showed comparable fatigue performance to traditional hot mixed asphalt without RAP. The reduced construction temperature of WMA technology reduces binder oxidation during production, consequently decreasing mixture stiffness that might otherwise result in cracking. Therefore, use of WMA is an effective mechanism for incorporating waste materials 
in asphalt production more frequently, an end which is in harmony with the goals of sustainable pavement construction.
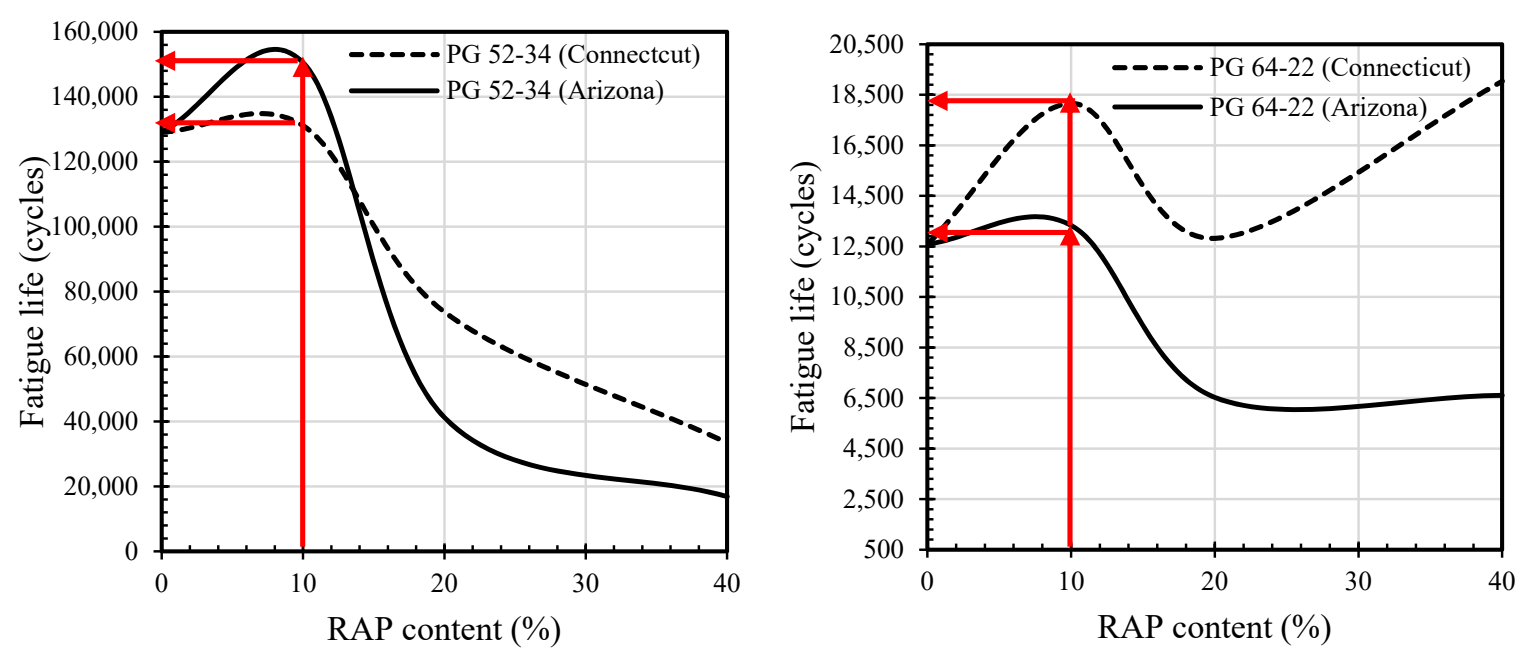

Figure 2. Correlation of fatigue life and RAP content which is based on flexural fatigue tests based on data reported by Hajj et al. [19].

Traditionally, airports have generally resisted using RAP in their runway surfaces due to concerns regarding performance and durability in a high-risk environment under severe loads. However, in 2018, two Australian airports incorporated RAP from temporary construction ramps built from the same asphalt mixture design into their runways. This design is referred to as low-risk RAP and contains a modest 5-10\% RAP [24]. No adverse effects were observed, except that friction in wet conditions was reduced for sections containing RAP (Figure 3).

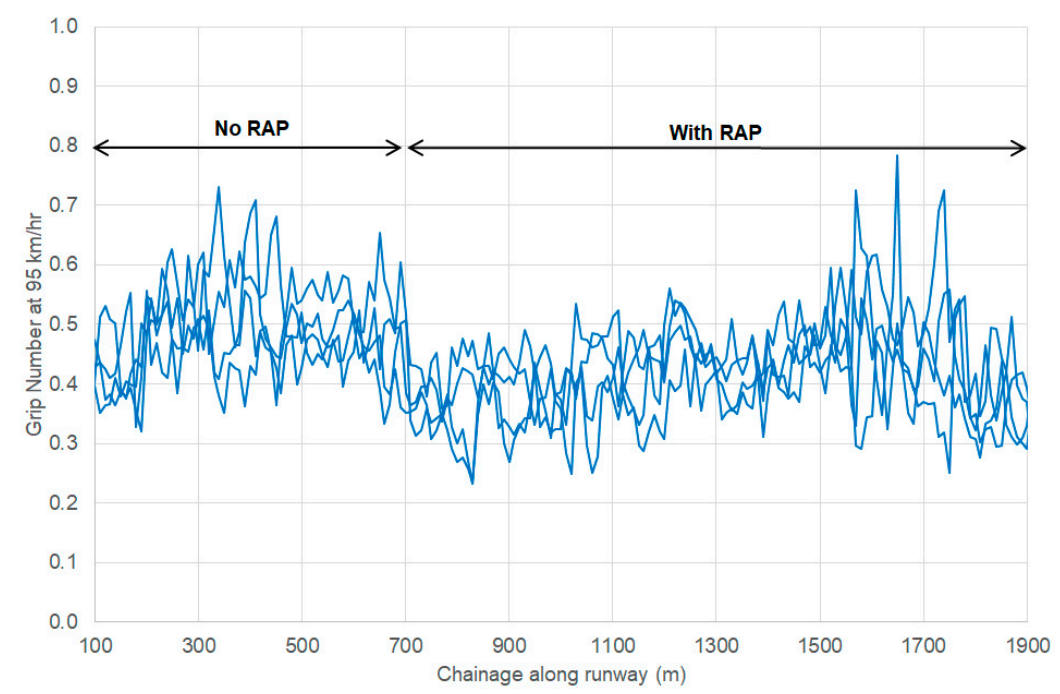

Figure 3. Effect of RAP on wet runway friction, plotted based on data from White [24].

\subsection{Waste Plastic}

Global concern regarding the environmental challenge associated with plastic products is increasing. There are also concerning statistics regarding the use of plastics in different countries. For example, it has been reported that the world generates a million plastic bottles every minute [25] with less than half of those collected for recycling and less than $7 \%$ incorporated back into plastic bottle production. It is also predicted that the oceans will contain more plastic (by mass) than fish by the year 2050 [26]. In Australia, plastic bags are a significant contributor to overall waste plastic with over 
30 million plastic bags entering the environment per year [27], while in Europe, over 3 million tonnes of plastic bags were produced in 2008 and in 2010 only $6 \%$ were recycled [28,29].

One effective remedy is to use the waste plastic as an alternative construction material. For example, it can be used as a binder extender in the asphalt mixtures. The high melting temperature, high decomposition temperature and resistance to UV (ultraviolet) radiation effectively consume waste plastic while reducing the quantity of new bitumen required for asphalt production. There are also waste plastic-based modifiers of binder for the production of asphalt with enhanced performance properties. Table 1 shows engineering properties of three commercially available waste plastic-based asphalt extenders.

Table 1. Engineering properties and physical states of waste plastic-based asphalt modifier.

\begin{tabular}{|c|c|c|c|}
\hline Product Name & Binder Replacement & Intended Use & Physical Appearance \\
\hline MR6 & $\begin{array}{l}6-10 \% \text {, with } 6 \% \\
\text { recommended as optimal }\end{array}$ & $\begin{array}{c}\text { Performance enhancement with } \\
\text { a focus on deformation } \\
\text { resistance }\end{array}$ & \\
\hline MR8 & $\begin{array}{c}6-10 \% \text {, with } 6 \% \\
\text { recommended as optimal }\end{array}$ & $\begin{array}{l}\text { Cost reduction with similar or } \\
\text { better performance }\end{array}$ & \\
\hline MR10 & $\begin{array}{c}6-10 \% \text {, with } 6 \% \\
\text { recommended as optimal }\end{array}$ & $\begin{array}{l}\text { Performance enhancement with } \\
\text { a focus on fracture resistance }\end{array}$ & \\
\hline
\end{tabular}

To evaluate the performance of MR6, MR8 and MR10, White and Reid [30] carried out laboratory tests. The optimum percentage (6\%) was used for all the samples. The results showed that the rut depth decreases significantly due to incorporation of waste plastic (Figure 4). Also, Figure 4a shows that the MR6-modified samples had the minimum rut depth. Following by that, MR10 and MR8 showed lower rut depth, respectively. The reason is that incorporation of waste plastic can upgrade asphalt binder, which increases the structural capacity of the mixture.

Furthermore, Figure $4 \mathrm{~b}$ shows that the fracture toughness of samples incorporating waste materials was higher than the control sample. The fracture toughness of the samples containing MR was $22 \%$ higher than that of control mix, indicating higher fracture toughness. Therefore, the MR6 modified asphalt showed the maximum crack resistance, as well as the highest deformation resistance, indicating a performance improvement similar to that associated with conventional polymer modifiers for bituminous binder production. 


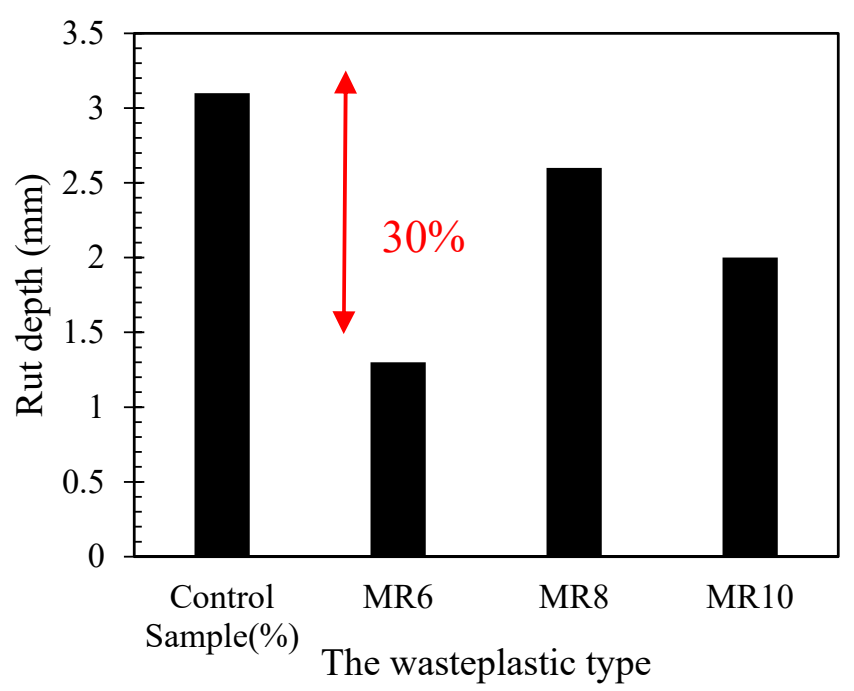

(a) Rut depth

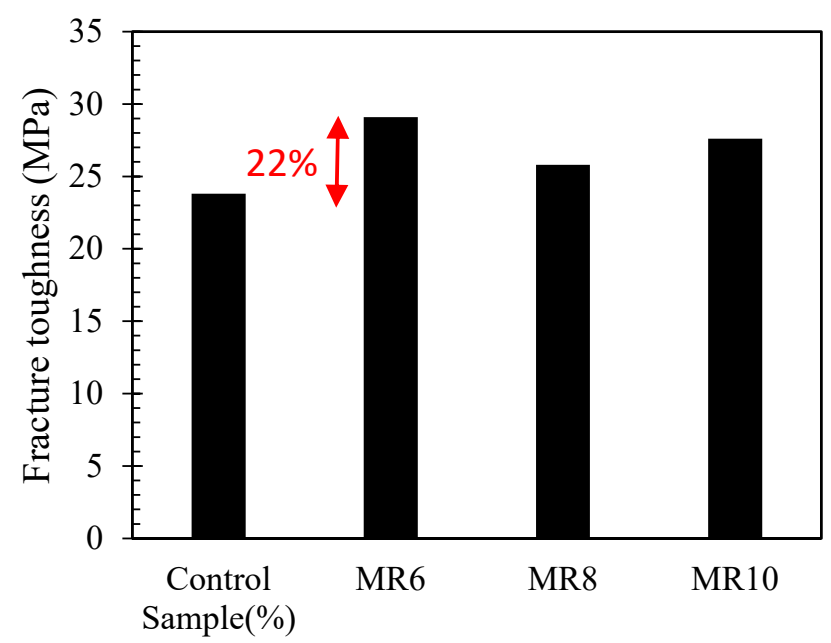

The wasteplastic type

(b) Fracture toughness

Figure 4. Effect of MR6, MR8 and MR10 on the performance of the mixture, plotted based on data reported by White and Reid [29].

\subsection{Blast Furnace Slag}

Based on technical performance, BFS is ranked as the second most desirable reusable material for highway pavement construction, while it is ranked fifth and sixth in economic and environmental terms, respectively [5]. There are three main types of slag: iron blast furnace slag, oxygen furnace steel slag, and electric arc furnace slag. BFS is available in four main forms: air-cooled, pelletised, granulated, and ground.

This paper only covers the application of the ground and granulated varieties of BFS (GGBFS). GGBFS can be used as a filler in asphalt as well as a supplementary cementitious material in concrete pavement. Although BFS is a free material (as an industrial by-product), the energy required for the crushing and grinding of BFS should be included in the input energy calculations of the raw materials phase. For example, Lippiatt [31] estimated that the input energy required for the processing of slag is $722 \mathrm{~kJ} / \mathrm{kg}$. Notably, BFS is a hydrophobic material and has high absorption. As a consequence, the OBC of asphalt mixtures containing BFS is higher than that of control asphalt mixtures, which reduces the environmental benefit. Because of the higher $\mathrm{OBC}$, mixtures containing $\mathrm{BFS}$ are prone 
to asphalt bleeding at higher temperatures. Asphalt bleeding is a functional failure that decreases the skid resistance of the pavement surface which negatively impacts safety. Therefore, optimal BFS content for asphalt mixtures should be determined individually for various asphalt types and service conditions. Asi [32] recommends the maximum skid resistance associated with mixtures containing $30 \% \mathrm{BFS}$; however, optimal BFS content is likely to be mixture-specific.

Analysis of structural consistency of asphalt mixtures containing BFS indicates a decrease in rutting potential [33,34]. Moreover, analysis of long-term performance ageing found that BFS mixtures had higher stiffness, reflecting the higher absorption of the binder by BFS granules, resulting in a reduced effective binder content. It follows that mixtures containing BFS are more prone to ageing, which may reduce the service life of asphalt surfaces. However, physicochemical ageing depends on many factors, including construction temperature, aggregate type and gradation, binder type, ambient temperature, service condition, field compaction and densification due to traffic loading. Further investigation on the short and long-term ageing patterns of BFS mixtures is required. Additional research should also be conducted on the synergistic performance of BFS and WMA, because the higher stiffness of BFS mixtures might be offset by the reduced binder ageing associated with WMA production temperatures.

Use of BFS as a supplementary cementitious material in concrete also increases the sustainability of concrete pavements. The main disadvantage of using BFS in concrete pavements is slower early-life strength gain which may result in longer curing periods and delays in opening pavements to traffic. Chemical additives can be used to accelerate the hydration of the cement paste and reduce curing time. However, incorporation of extra chemical materials reduces the sustainability benefits associated with the incorporation of BFS. The benefits and drawbacks of its use should be considered in LCA analysis.

It is also important to understand that the environmental footprint associated with different BFS sources can be significantly different. For example, Crossin [35] and Palankar et al. [36] reported that the use of BFS can decrease greenhouse gas emission by around $50 \%$, while a LCA case study conducted by Li et al. [37] showed that the total environmental emissions decrease by only $7 \%$, a result which is consistent with the findings of Boesch \& Hellweg [38]. The source of these differences could be assessed by various methods in LCA analysis, weighing factors such as unit function, construction technology, service condition, raw material type, mode of transportation, energy cost and productivity, technical skills and site conditions.

\subsection{Recycled Glass}

Glass production technology is resource- and energy-intensive. Waste glass or recycled glass can be used as either a coarse or fine aggregate and filler in asphalt mixtures [39-41]. Moreover, glass particles are hydrophobic with low water absorption ( $0.3 \%$ to $0.4 \%)$ [39]. Consequently, asphalt binders are not absorbed by glass particles. The OBC of asphalt mixtures containing glass is less than for comparable traditional asphalt mixtures. This discrepancy means that binder contents must be reduced, or else air void volume may be inadvertently impacted. Furthermore, Moreneo et al. [42] reported that stability decreases and air voids increase as recycled glass concentration increases. The low absorption capacity of recycled glass reduces aggregate-binder adhesion by limiting bituminous binder absorption. This unabsorbed binder attracts compaction energy, resulting in less efficient absorption by the aggregate materials. As a result, less interlock is achieved between aggregate particles, reducing the load-bearing capacity of the mixture (which becomes more dependent on the stiffness of the binder rather than on the friction between the aggregate particles). It should be noted that asphalt surface interface strength is also a function of adhesion, friction and aggregate embedment or interlock [39] and may be adversely affected by high recycled glass content.

It should be noted that OBC decreases as the glass content increases. However, a laboratory study conducted by Hughes [43] showed that glass contents up to $15 \%$ had no adverse effect on the ITS and resilient modulus, which are factors influencing the load-bearing capacity of the mixture. Also, incorporation of $15 \%$ waste glass actually improved the fatigue life of the asphalt mixture. Therefore, $15 \%$ can be considered the optimum content of recycled glass in asphalt mixtures. 
Recycled glass was also used as a coarse and fine aggregate in concrete pavements. Experimental results indicated that the use of waste glass as a course aggregate reduced the concrete's compressive strength [44-46]. In contrast, fine-graded glass for sand replacement increased the compressive strength [47-49]. This reflects the strength gain of concrete as a hydration reaction. Since the surface area of fine-graded glass particles is higher than that of course glass particles, the reaction potential of the glass particles increases during hydration. Consequently, hydration products increase and the strength of the concrete increases.

Safety must also be considered when recycled glass asphalt pavement utility is assessed. Vehicles can dislodge glass particles from segregated pavement surfaces that can damage vehicles and injure pedestrians [39]. Therefore, recycled glass is only recommended for surfacing of low volume and low speed roads, for road base, and recreational pavements such as footpaths. Recycled glass is not recommended for the surface layer of highways or for airport pavements because the high shear stresses may dislodge glass particles and cause damage to vehicles and aircraft. Also, shear-related distress may result in delamination at the surface layer, or excessive shear creep within the asphalt surface layer as a result of the reduced asphalt internal friction and adhesion [50].

In addition, safety is an important consideration during the construction phase because sharp glass particles may injure paving crew members. Moreover, members of the paving crew might inhale glass dust. However, Disfani et al. [51] reported that larger (9.5-mm diameter) glass particles do not present a safety concern, based on experimental studies and field investigations, which agrees with previous research by Larsen [52]. Furthermore, Landris [53] reported that even particles smaller than $9.5 \mathrm{~mm}$ did not present a safety risk to asphalt paving crews as long as goggles and gloves are worn.

\section{Challenges for Using Waste Materials in Pavements}

Although there are many advantages to using waste materials in pavement construction, a large initial investment is necessary to develop infrastructure for sorting the materials based on type, source and risk. In addition, waste materials should be processed to meet the requirements for use in pavements. The use of waste materials requiring advanced technology to process may appear unappealing at first glance. For instance, using waste materials incurs costs through necessitating the construction of facilities and training workforces, however, the cost of pavement construction and rehabilitation decrease in the long-term.

The potential difficulties of using waste materials in pavement construction can be illustrated by considering the recycling process of glass as an example. There are optical sensors that detect and sort waste glass based on colour [40], and since glass colour is related to its chemical composition, the durability of the resulting asphalt and concrete mix can be affected. A potential solution to such logistical issues could be investment by private sectors in the development of recycling infrastructure based on public-private partnerships. Additionally, contractors and pavement technologists could be incentivised to use waste materials through tax exemption. Such policies have been very successful in encouraging sustainable production in China [54]. Furthermore, pavement engineers, material technologists and paving crews should be trained to use different types of waste materials for pavement construction. To facilitate this, detailed technical guidance and practice codes should be provided. Although such technical codes were created for the use of RAP, there are no standardised practice codes for the use of waste glass, plastic or blast furnace slag.

To produce more environmentally friendly asphalt and concrete mixes, it is recommended to use different combinations of waste materials. However, the long-term performance of such pavements is a cause for concern. To address this issue, optimal combinations of various waste materials should be determined through laboratory experimentation. A key factor in determining such a balance is the compatibility between different waste materials types. In other words, synergistic effects between the waste materials, binder and aggregate materials is desirable.

Another challenge for using waste material is the potential production of leachate, which can be hazardous for eco-systems. Therefore, the chemical composition of leachates should be investigated. 
There are conflicting reports and research results on the composition of leachate from pavement made using waste materials, and further investigation is required.

In addition, a pertinent question lies in how many times the waste materials can be recycled and reused for pavement construction. The appropriate number of uses depends on the type of waste material, its chemical components, energy feedstock, environmental emissions and economic justifications. A definitive answer that encompasses every composition is impossible. Therefore, it is necessary for various waste materials to be ranked based on their potential for recyclability. Further research is necessary to establish a multi-variable criterion for ranking different waste materials.

\section{Conclusion}

Four different waste materials used for pavement construction were reviewed. These materials are widely available and provide benefits in terms of structural and functional performance, cost, and most importantly to environment sustainability. RAP is used in asphalt mixtures, while BFS, waste plastic and glass can be used for both asphalt and concrete pavements. These materials have different effects on the engineering properties of the pavement, impacting its structural, functional and environmental performance, necessitating further study to optimize their effective use. Although the results of laboratory studies demonstrate the benefits of using these waste materials, only limited real-world use of recycled glass, plastic waste and BFS has been reported. In contrast, RAP is well-established as a reusable material in asphalt mixtures. Increased use of recycled materials is expected in the future, as confidence in pavement performance increases and pavement owners become more focused on environmental sustainability. However, capital investment, lack of technical guidance, environmental concerns regarding leachate production and recyclability, are challenges for the use of waste materials in pavement construction.

Author Contributions: The authors A.J. and G.W. collected the literature from different sources. Then, they discussed on every literature. Finally, the paper was written based on a close collaboration. All authors have read and agreed to the published version of the manuscript.

Funding: This research received no external funding.

Conflicts of Interest: The authors declare no conflict of interest.

\section{References}

1. Huang, Y.H. Pavement Analysis and Design, 2nd ed.; Pearson Education Inc.: New York, NY, USA, 2004; pp. $1-711$.

2. Daniels, G.; David, R.E.; Stockton, W.R. Techniques for Manually Estimating Road User Costs Associated with Construction Projects; Texas Transportation Institute, Texas A M University: College Station, TX, USA, 1999; pp. 1-104.

3. Austroads, Impact of Climate Change on Road Infrastructure, APR-243; Austroads: Sydney, Australia, 2004; pp. 1-142.

4. Koetse, M.J.; Rietveld, P. The impact of climate change and weather on transport: An overview of empirical findings. Transp. Res. Part D Transp. Environ. 2009, 14, 205-221. [CrossRef]

5. Ahmed, I. Use of Waste Materials in Highway Construction; Elsevier: London, UK, 1993; pp. 1-115.

6. Gannon, C.R.; Wombles, R.H.; Ramcy, C.A.; Daris, J.P.; Little, W.V. Recycling conventional and rubberized bituminous concrete pavement using recycling agents (a laboratory and field study). In Asphalt Paving Technology; Proceeding Association of Asphalt Technologists: Louisvile, KY, USA, 1980.

7. Imtiaz, A.; Lowel, C.W. Use of Waste materials in highway construction: State of the practice and evaluation of the selected waste products. J. Transp. Res. Rec. 1992, 1345, 1-9.

8. Santero, N.; Loijos, A.; Ochsendorf, J. Greenhouse gas emission reduction opportunities for concrete pavements Infrastructure. J. Ind. Ecol. 2013, 17, 859-868. [CrossRef]

9. Carpenter, A.C.; Gardner, K.H. Use of industrial by-products in urban roadway infrastructure. J. Ind. Ecol. 2009, 13, 965-977. [CrossRef] 
10. West, R.; Coupland, A. High RAP asphalt pavements: Japan practice-lessons learned. In National Asphalt Pavement Association 2015; Information Seri: Washington, DC, USA, 2015; pp. 1-62.

11. Anthonissen, J.; Van Der Bergh, W.; Braet, J. Review and environmental impact assessment of green technologies for base courses in bituminous pavements. Environ. Impact Assess. Rev. 2016, 60, 139-147. [CrossRef]

12. Lee, J.C.; Edil, B.E.; Tinjum, J.M.; Benson, C.H. Quantitive assessment of environmental and economy benefits of recycled materials in highway construction. J. Transp. Res. Rec. 2010, 2158, 138-142. [CrossRef]

13. Jamshidi, A.; Hamzah, M.O.; Shahadan, Z.; Yahaya, A. Evaluation of the rheological properties and activation energy of asphalt binders blended with different percentages of recovered binders from different sources at high and intermediate temperatures. J. Mater. Civ. Eng. 2014, 27, 1-9.

14. Jamshidi, A.; Hamzah, M.O.; Shahadan, Z. Selection of reclaimed asphalt pavement sources and contents for asphalt mix production based on asphalt binder rheological properties, fuel requirements and greenhouse gas emissions. J. Clean. Prod. 2012, 23, 20-27. [CrossRef]

15. Jamshidi, A.; White, G.; Hosseinpour, M.; Kurumisawa, K.; Hamzah, M.O. Characterization of effects of reclaimed asphalt pavement (RAP) source and content on dynamic modulus of hot mix asphalt concrete. Constr. Build. Mater. 2019, 217, 487-497. [CrossRef]

16. Shahadan, Z.; Hamzah, M.O.; Yahya, A.S.; Jamshidi, A. Evaluation of the dynamic modulus of asphalt mixture incorporating reclaimed asphalt pavement. Indian J. Eng. Mater. Sci. 2013, 20, 376-384.

17. Jamshidi, A.; Hamzah, M.O.; Kurumisawa, K.; Nawa, T.; Samali, B. Evaluation of sustainable technologies that upgrade the binder performance grade in asphalt pavement construction. J. Mater. Des. 2016, 95, 9-20. [CrossRef]

18. Goh, S.; You, Z. Properties of Asphalt Mixtures with RAP in the Mechanistic-empirical pavement design of flexible pavements: A Preliminary Investigation. In Airfield and Highway Pavements; American Society of Civil Engineers: Reston, VA, USA, 2008; pp. 171-181. [CrossRef]

19. Hajj, E.Y.; Sebally, P.E.; Kandia, P. Use of reclaimed asphalt pavements (RAP) in airfields HMA pavements. In AAPTP Project 05-06; Department of Civil and Environmental Engineering College of Engineering University of Nevada Reno: Reno, NV, USA, 2008; pp. 1-136.

20. Ziari, H.; Aliha, M.R.M.; Moniri, A.; Saghafi, Y. Crack resistance of hot mix asphalt containing different percentages of reclaimed asphalt pavement and glass fiber. J. Constr. Build. Mater. 2020, 230, 1-10. [CrossRef]

21. Daryaee, D.; Ameri, M.; Mansourkhaki, A. Utilizing of waste polymer modified bitumen in combination with rejuvenator in high reclaimed asphalt pavement mixtures. J. Constr. Build. Mater. 2020, 235, 1-35. [CrossRef]

22. Lu, D.X.; Saleh, M. Laboratory evaluation of warm mix asphalt incorporating high RAP proportion by using evotherm and sylvaroad additives. J. Constr. Build. Mater. 2016, 114, 580-587. [CrossRef]

23. Martinho, F.C.G.; Picado-Santos, L.G.; Capitão, S.D. Mechanical properties of warm-mix asphalt concrete containing different additives and recycled asphalt as constituents applied in real production conditions. J. Constr. Build. Mater. 2017, 131, 78-89. [CrossRef]

24. White, G. Quantifying the impact of reclaimed asphalt pavement on airport asphalt surfaces. J. Constr. Build. Mater. 2019, 197, 757-765. [CrossRef]

25. Laville, S.; Taylor, M. A Million Bottles a Minute: World's Plastic Binge as Dangerous as Climate Change. The Guardian: Australian Edition. Available online: www.theguardian.com/environment/2017/jun/28/a-mill ion-a-minute-worlds-plastic-bottle-binge-as-dangerous-as-climate-change (accessed on 10 April 2018).

26. EMF. The New Plastics Economy: Rethinking the Future of Plastics. Available online: https://www.ellenmacar thurfoundation.org/assets/downloads/EllenMacArthurFoundation_TheNewPlasticsEconomy_15-3-16.pdf (accessed on 19 January 2016).

27. Ting, J. Plastic, Like Diamonds, Is Forever: Time to Use Fewer Bags. The Conversation. Available online: https://theconversation.com/plastic-like-diamonds-is-forever-time-to-use-fewer-bags-7736 (accessed on 26 June 2012).

28. Euro Comission. Commission Seeks Views on Reducing Plastic Bag Use. European Commission Press Release, IP/11/80, Brussells, Belgium, 18 May 2011. Available online: https://theconversation.com/plastic-like -diamonds-is-forever-time-to-use-fewer-bags-7736 (accessed on 18 June 2011). 
29. White, G.; Reid, G. Recycled waste plastic for extending and modifying asphalt binders. In Proceedings of the Symposium on Pavement Surface Characteristics (SURF) 2018, Brisbane, Queensland, Australia, 2-4 May 2018; pp. 1-18.

30. White, G.; Reid, G. Recycled waste plastic modification of bituminous binder. In Proceedings of the International Conference on Bituminous Mixtures and Pavements 2019, Thessaloniki, Greece, 12-14 June 2019; pp. 1-13.

31. Lippiatt, B. BEESRG 4.0: Building for Environmental and Economic Sustainability-Technical Manual and User Guide; National Institute of Standards and Technology: Gaithersburg, MD, USA, 2007; pp. 1-313.

32. Asi, I.M. Evaluating skid resistance of different asphalt concrete mixes. Build. Environ. 2007, 42, 325-329. [CrossRef]

33. Airey, G.D.; Collop, A.C.; Thom, N.H. Mechanical performance of asphalt mixtures incorporating slag and glass secondary aggregates. In Proceedings of the 8th Conference on Asphalt Pavements for Southern Africa, Sun City, South Africa, 12-16 September 2004.

34. Ellis, C.; Zhao, B.; Bames, J.; Jones, N. Properties of GGBS-bitumen emulsion systems with recycled aggregates. Road Mater. Pavement Des. 2004, 5, 373-383. [CrossRef]

35. Crossin, E. The greenhouse gas implications of using ground granulated blast furnace slag as a cement substitute. J. Clean. Prod. 2015, 95, 101-108. [CrossRef]

36. Palankar, N.; Shankar, A.R.; Mithun, B. Durability studies on eco-friendly concrete mixes incorporating steel slag as coarse aggregates. J. Clean. Prod. 2016, 129, 437-448. [CrossRef]

37. Li, Y.; Liu, Y.; Gong, X.; Nie, Z.; Cui, S.; Wang, Z.; Chen, W. (Environmental impact analysis of blast furnace slag applied to ordinary Portland cement production. J. Clean. Prod. 2016, 120, 221-230. [CrossRef]

38. Boesch, M.E.; Hellweg, S. Identifying improvement potentials in cement production with life cycle assessment. Environ. Sci. Technol. 2010, 44, 9143-9149. [CrossRef] [PubMed]

39. Choudhary, J.; Kumar, B.; Gupta, A. Utilization of solid waste materials as alternative fillers in asphalt mixes: A review. J. Constr. Build. Mater. 2020, 234,1-19. [CrossRef]

40. Jamshidi, A.; Kurumisawa, K.; Nawa, T.; Igarashi, T. Performance of pavements incorporating waste glass: The current state of the art. Renew. Sustain. Energy Rev. 2016, 64, 211-236. [CrossRef]

41. Hasan, M.R.M.; Chew, J.W.; Jamshidi, A.; Yang, X.; Hamzah, M.O. Review of sustainability, pre-treatment, and engineering considerations of asphalt modifiers from the industrial solid wastes. J. Traffic Transp. Eng. Engl. Ed. 2019, 6, 209-244.

42. Moreno-Navarro, F.; Perez-Martinez, M.; Martín-Marín, J.; Sol-Sanchez, M.; Rubio-Gámez, M.C. Mechanical performance of asphalt mixes incorporating waste glass. Balt. J. Road Bridge Eng. 2015, 10, 1-10. [CrossRef]

43. Hughes, C.S. Feasibility of using recycled glass in asphalt mixes. In Report No. VTRC 90-R3; Virginia Transportation Research Council: Albemarle, VA, USA, 1990; pp. 1-32.

44. Topcu, B.; Canbaz, M. Properties of concrete containing waste glass. J. Cem. Concr. Res. 2004, 34, $267-274$. [CrossRef]

45. Park, S.B.; Lee, B.C.; Kim, J.H. Studies on mechanical properties of concrete containing waste glass aggregate. J. Cem. Concr. Res. 2004, 34, 2181-2189. [CrossRef]

46. De Castro, S.; De Brito, J. Evaluation of the durability of concrete made with crushed glass aggregates. J. Clean. Prod. 2013, 4, 7-14. [CrossRef]

47. Batayneh, M.; Marie, I.; Asi, I. Use of selected waste materials in concrete mixes. Waste Manag. 2007, 27, 1870-1876. [CrossRef]

48. Malik, M.I.; Bashir, M.; Ahmad, S.; Tariq, T.; Chowdhary, U. Study of concrete involving use of waste glass as partial replacement of fine aggregates. IOSR J. Eng. 2013, 3, 8-13. [CrossRef]

49. Shao, Y.; Lefort, T.; Moras, S.; Rodriguez, D. Studies on concrete containing ground waste glass. J. Cem. Concr. Res. 2000, 30, 91-100. [CrossRef]

50. White, G. State of the art: Interface shear resistance of asphalt surface layers. Int. J. Pavement Eng. 2016, 18, 887-901. [CrossRef]

51. Disfani, M.; Arulrajah, A.; Bo, M.W.; Sivakugan, N. Environmental risks of using recycled crushed glass in road applications. J. Clean. Prod. 2012, 20, 170-179. [CrossRef]

52. Larsen, D. Feasibility of utilizing waste glass in pavements. In Report No. 343-21-89-6; Connecticut Department of Transportation: Newington, CT, USA, 1989; pp. 1-27. 
53. Landris, T.L. Recycled glass and degraded materials. In US Army Corps of Engineering; Engineer Research and Development Center: Vicksburg, MS, USA, 2007; pp. 1-150.

54. Li, W.; Lin, W. Circular Economy Policies in China. ERIA Research Project Report. In Towards a Circular Economy: Corporate Management and Policy Pathways; ERIA: Jakarta, Indonesia, 2014; pp. 95-111.

(C) 2019 by the authors. Licensee MDPI, Basel, Switzerland. This article is an open access article distributed under the terms and conditions of the Creative Commons Attribution (CC BY) license (http://creativecommons.org/licenses/by/4.0/). 